\title{
TIME-DEPENDENT POLAR WIND MODELING
}

\author{
T. I. Gombosi and A. F. Nagy \\ Space Physics Research Laboratory, Department of Atmospheric, Oceanic and \\ Space Sciences, The University of Michigan, Ann Arbor, MI 48109, U.S.A.
}

\begin{abstract}
In the presence of a strong magnetic field (such as the geomagnetic field) the plasma tends to flow along the magnetic field lines, therefore in most ionospheric flow calculations the use of the gyrotropic approximation is justified. In the first part of this paper it is shown that the gyrotropic twenty moment approximation is equivalent to the gyrotropic sixteen moment approximation. The second part of the paper is devoted to the study of return current generated polar wind transients. Ionospheric return currents generate significant downward heavy ion flows in the topside ionosphere with peak values well exceeding $10^{8} \mathrm{~cm}^{-2} \mathrm{~s}^{-1}$. When the return current ceases the polar ionosphere rapidly returns to its previous equilibrium state. During the recovery phase of the return current event an upward propagating heavy ion transient is formed, which is mainly characterized by a relatively short $\mathrm{O}^{+}$upwelling event. The $\mathrm{H}^{+}$escape flux remains relatively constant (within 10-20\%) during field-aligned current events.
\end{abstract}

\section{INTRODUCTION}

The possibility of high speed ionospheric plasma outflows along open geomagnetic field lines was originally suggested by Axford /1/ and Banks and Holzer /2/. The existence of the polar wind was first demonstrated experimentally by Hoffman $/ 3 /$, who observed $\mathrm{H}^{+}$ion flow velocities of up to $10 \mathrm{~km} / \mathrm{s}$ parallel to the geomagnetic field and flux levels of the order of $10^{8} \mathrm{~cm}^{-2} \mathrm{~s}^{-1}$ above $\sim 2500 \mathrm{~km}$. Upward flows of $\mathrm{O}^{+}$ions were first observed near the auroral oval by the ion mass spectrometer on board the $\$ 3-3$ satellite $/ 4,5 \%$. The first quantitative measurements of the polar wind behavior were obtained by the retarding ion mass spectrometer onboard the Dynamics Explorer 1 (DE1) satellite, which observed supersonic $\mathrm{H}^{+}$ion flows $/ 6 /$. Large fluxes $\left(>10^{8} \mathrm{~cm}^{-2} \mathrm{~s}^{-1}\right)$ of low energy $(<10 \mathrm{eV}) \mathrm{O}^{+}$ ions flowing up along polar cap field lines have also been observed by the DE-1 particle detectors $\pi /$. Yau et al. $/ 8 /$ have estimated that the occurrence frequency of upflowing energetic $\mathrm{O}^{+}$ions $(>10 \mathrm{eV})$ is quite large in the auroral region and as large as 0.3 even within the polar cap.

During the last decade a variety of approaches have been introduced to model polar wind flows, including steady-state hydrodynamic, magnetohydrodynamic, kinetic and semikinetic approximations (cf. $19 /$ ). A common feature of these steady-state "classical" polar wind calculations was that they were unable to describe heavy ion outflows. Modeling of the observed heavy ion upflows is clearly not possible with "classical" steady-state polar wind calculations without additional assumptions (for example, in order to obtain significant levels of steady-state $\mathrm{O}^{+}$outflows Barakat and Schunk /10/ assumed significantly elevated electron temperatures). By the mid-1980s a new generation of highlatitude ionospheric transport calculations began to emerge. Mitchell and Palmadesso /11/ developed a time-dependent model describing the upper segment of an auroral field line (extending from the topside ionosphere well into the polar magnetosphere). Their original model was based on mobile electrons and $\mathrm{H}^{+}$ions and a stationary, isothermal $\mathrm{O}^{+}$ background. Singh and Schunk $/ 12,13 /$ carried out a time-dependent study of ion acceleration in isothermal plasmas, expanding along high altitude open magnetic field lines. When studying the temporal evolution of the plasma characteristics, both Mitchell and Palmadesso/11/ and Singh and Schunk/12,13/ had to introduce an already established high speed flow at the lower boundary into the collisionless high altitude region. A time-dependent six moment approximation of the interhemispheric flow along closed magnetic field lines was considered by Khazanov et al. $/ 14 /$ to investigate the refilling process of depleted plasmaspheric field lines.

Comprehensive time-dependent hydrodynamic polar wind models were developed almost simultaneously by Zinin et al. $/ 15 /$ and by Gombosi et al. $16,17 \%$. Zinin et al. $/ 15 /$ solved the continuity, momentum and energy equations for oxygen and hydrogen ions as well as for electrons along auroral field lines between altitudes of $126 \mathrm{~km}$ and $10 \mathrm{R}_{\mathrm{E}}$, and investigated the typical time scales of the various plasma components. Gombosi et al. /16, 17/ simultaneously solved the coupled continuity, momentum and energy equations of a two ion $\left(\mathrm{H}^{+}\right.$and $\left.\mathrm{O}^{+}\right)$quasi-neutral plasma, along a diverging flux tube, between 200 and $8000 \mathrm{~km}$, taking into account the effects of ionization, charge exchange, recombination, collisions, heat conduction and external heat sources. This model was the first to describe transient heavy ion upward flows generated by short duration ion and/or electron heating processes at lower altitudes /17, 18/. Recently a comparative study of this latter hydrodynamic model and a simplified collisionless model with anisotropic temperatures was carried out by Gombosi and Schunk /19\%. These authors concluded that qualitatively the two models predict the same temporal characteristics for the polar wind densities, velocities and escape fluxes. In addition to the interesting new results this study has also achieved an important benchmarking between these numerically fairly complicated models. 
Most recently several theoretical papers were published about the effect of field-aligned return currents on the polar wind. Schunk et al. 20 / investigated the electron thermal structure in the presence of ionospheric return currents. This model followed flux tubes of low speed plasma as they convected through the neutral atmosphere. The continuity, momentum and a simplified energy equations were solved in this model over an altitude range from 120 $\mathrm{km}$ to $800 \mathrm{~km}$, with boundary conditions describing chemical equilibrium at $120 \mathrm{~km}$ and no outflow at $800 \mathrm{~km}$. On the other hand Ganguli and Palmadesso /21/ and Ganguli et al. $/ 22 /$ investigated the effects of return currents on the high altitude collisionless region. These authors solved the steady-state, sixteen moment approximation of the gyrotropic transport equations for electrons and $\mathrm{H}^{+}$ions, while the $\mathrm{O}^{+}$ions were assumed to form a static background population at a constant temperature. Their calculations start at an altitude of $1500 \mathrm{~km}$ and extend to $10 \mathrm{R}_{\mathrm{E}}$; they assumed a supersonic upward $\mathrm{H}^{+}$flow at the lower boundary. Ganguli and Palmadesso $/ 21 /$ have also studied timedependent, high altitude $\mathrm{H}^{+}$transient behavior generated by ionospheric return currents; to do this they used an earlier model of Mitchell and Palmadesso /11/. On the basis of their model calculations, Ganguli and Palmadesso /21/ concluded that an increase in the return current results in faster electron upflow, which in turn implies a faster expansion of the electron gas and a cooler electron temperature. The reduced electron temperature leads to a reduction of the ambipolar electric field, which in turn results in a decrease of the hydrogen ion flow velocity.

The present paper summarizes the gyrotropic transport equations generally used to model plasma flows along open geomagnetic field lines. Special attention is paid to the simplifications and assumptions generally used to obtain equations describing the polar wind. In the second part of this paper a new set of model calculations is presented to describe transient features generated by field-aligned return currents in the polar ionosphere. The model concentrates on the altitude region where the polar ionosphere attains significant flow velocities (between $500 \mathrm{~km}$ and $1500 \mathrm{~km}$ ). One of the main advantages of this model is that it self-consistently calculates the ion densities, velocities and temperatures beginning from the low altitude photochemically controlled region.

\section{GYROTROPIC TRANSPORT EQUATIONS}

Several detailed summaries of the transport equations of the ionospheric plasma are available in the literature /23-27/. In this section we concentrate on an interesting and little noticed aspect of the gyrotropic transport equations.

The transport of a charged particle species, "s", is described by the Boltzmann equation:

$$
\frac{\partial F_{s}}{\partial t}+\left(c_{s i}+u_{s i}\right) \frac{\partial F_{s}}{\partial x_{i}}+\left\{G_{i}+\frac{e_{s}}{m_{s}} \varepsilon_{i j k}\left(c_{s j}+u_{s j}\right) B_{k}-\left(c_{s j}+u_{s j}\right) \frac{\partial u_{s i}}{\partial x_{j}}\right\} \frac{\partial F_{s}}{\partial c_{s i}}=\frac{\delta F_{s}}{\delta t}
$$

where $t=$ time, $x_{i}=$ spatial coordinates $(i=1,2,3), c_{s i}=$ random velocity components, $u_{s i}\left(t, x_{i}\right)=$ bulk flow velocity of species "s", $F_{s}\left(t, x_{i}, c_{s i}\right)=$ distribution function of particles "s", $G_{i}=$ local gravitational acceleration, $E_{i}=$ electric field vector, $B_{i}=$ magnetic field vector, $m_{s}=$ particle mass, $e_{s}=$ particle charge, $\varepsilon_{i j k}=$ permutation tensor, and $\delta F_{s} / \delta t=$ rate of change of the distribution function due to interparticle collisions. Repeated indices indicate summation.

The generalized transport equations can be obtained from the Boltzmann equation by multiplying it with $\mathrm{m}_{\mathrm{s}}$ and taking the velocity moments (with respect of the random velocity). The zeroth moment yields the continuity equation

$$
m_{s} \frac{\partial n_{s}}{\partial t}+m_{s} u_{s i} \frac{\partial n_{s i}}{\partial x_{i}}+m_{s} n_{s} \frac{\partial u_{s i}}{\partial x_{i}}=m_{s} \dot{s}_{s}
$$

where $\mathrm{n}_{\mathrm{s}}$ is the particle number density and $\dot{S}_{\mathrm{s}}$ is the net particle production rate. The first moment of the Boltzmann equation is the momentum equation

$$
m_{s} n_{s} \frac{\partial u_{s i}}{\partial t}+m_{s} n_{s} u_{s j} \frac{\partial u_{s i}}{\partial x_{j}}+\frac{\partial P_{s i j}}{\partial x_{j}}-n_{s}\left\{m_{s} G_{i}+e_{s} E_{i}+e_{s} \varepsilon_{i j k} u_{s j} B_{k}\right\}=\dot{M}_{s i}
$$
where $\mathrm{P}_{\text {sij }}$ is pressure tensor and $\dot{\mathrm{M}}_{\mathrm{s}}$ is the first moment of the collision term. The second moment yields the
governing equation for the pressure tensor:

$$
\frac{\partial P_{s i j}}{\partial t}+u_{s k} \frac{\partial P_{s i j}}{\partial x_{k}}+P_{s i j} \frac{\partial u_{s k}}{\partial x_{k}}+P_{s i k}\left(\frac{\partial u_{s j}}{\partial x_{k}}+\frac{\partial u_{s k}}{\partial x_{j}}\right)+\frac{\partial Q_{s i j k}}{\partial x_{k}}-\frac{e_{s}}{m_{s}}\left(e_{i k l} P_{s k j}+\varepsilon_{j k l} P_{s k i}\right) B_{l}=\dot{P}_{s i j}
$$
where $\mathrm{Q}_{s i j k}$ is the heat flow tensor and $\dot{\mathrm{P}}_{\text {sij }}$ is the second moment of the collision term. Finally, the third moment of
the Boltzmann equation describes the evolution of the heat flow tensor:

$$
\begin{gathered}
\frac{\partial Q_{s i j k}}{\partial t}+u_{s l} \frac{\partial Q_{s i j k}}{\partial x_{1}}+Q_{s i j k} \frac{\partial u_{s l}}{\partial x_{1}}+Q_{s i j l} \frac{\partial u_{s k}}{\partial x_{1}}+Q_{s i k l} \frac{\partial Q_{s j}}{\partial x_{1}}+Q_{s j k l} \frac{\partial u_{s i}}{\partial x_{1}}+\frac{\partial R_{s i j k l}}{\partial x_{1}}- \\
\begin{aligned}
\frac{1}{m_{s} n_{s}}\left[P_{s i j} \frac{\partial P_{s k l}}{\partial x_{1}}+P_{s i k} \frac{\partial P_{s j l}}{\partial x_{1}}+P_{s j k} \frac{\partial P_{s i l}}{\partial x_{1}}\right]-\frac{e_{s}}{m_{s}}\left(e_{k m n} Q_{s i j m}+\varepsilon_{j m n} Q_{s i k m}+\varepsilon_{i m n} Q_{s j k m}\right) B_{n} \\
=Q_{s i j k}-\frac{1}{m_{s} n_{s}}\left[P_{s i j} \dot{M}_{s k}+P_{s i k} \dot{M}_{j}+P_{s j k} \dot{M}_{s i}\right]
\end{aligned}
\end{gathered}
$$


where $R_{s i j k l}$ is the fourth order pressure tensor, while $Q_{\text {sijk }}$ is the third moment of the collision term.

It should be noted that each moment equation contains the divergence of the next velocity moment of the distribution function, i.e., the continuity equation depends on the bulk flow velocity, the momentum equation contains the pressure tensor, the pressure equation contains the heat flow tensor and so on. This means that unless we truncate the expansion somewhere, we end up with an infinite number of transport equations. In ionospheric transport theory the infinite series of velocity moments is usually truncated by Grad's closing formula /28/:

$$
R_{s i j k l}=\frac{1}{m_{s} n_{s}}\left[P_{s i j} P_{s k l}+P_{s i k} P_{j l}+P_{s i l} P_{s j k}\right]
$$

Transport equations (2) to (5) constitute the twenty moment approximation (one continuity equation + three components of the momentum equation + six equations for the independent components of the symmetric pressure tensor + ten independent components of the heat flow tensor). This is the most general set of transport equations used in ionospheric applications.

In the remaining of this section the discussion is centered on the case of a strong external magnetic field. It is convenient to solve the transport equations in a coordinate system, where the average external electric field component perpendicular to the magnetic field is zero. It is always possible to choose such a coordinate system by an appropriate velocity transformation. In the case of the high latitude terrestrial ionosphere this coordinate system is moving horizontally, together with the convected plasma flow tubes. In this coordinate system the gyrotropic approximation can be obtained by taking the

$$
\mathbf{B}=|\mathbf{B}| \rightarrow \infty
$$

limit. It is also required that the transport equations ((2) to (5)) remain valid while $B \rightarrow \infty$; therefore it is required that the coefficients of the magnetic field should vanish in all the transport equations. This requirement does not lead to any restrictions in equation (2), because the continuity equation does not contain $\mathbf{B}$. The application of this gyrotropic condition to the momentum equation requires that

$$
\mathbf{u}_{\mathbf{s}} \times \mathbf{B}=\mathbf{0}
$$

Condition (7) means that the flow velocity has to be field aligned:

$$
\mathrm{u}_{\mathrm{si}}=\mathrm{u}_{\mathrm{s}} \mathrm{b}_{\mathrm{i}}
$$

Here $b_{i}=B_{i} / B$ are the components of the unit vector pointing along the magnetic field line. Equation (4) yields the following condition for the pressure tensor:

$$
\varepsilon_{\mathrm{ilk}} \mathrm{P}_{\mathrm{sjl}}+\varepsilon_{\mathrm{jlk}} \mathrm{P}_{\text {sil }}=0
$$

This condition is satisfied by the following form of the pressure tensor:

$$
P_{s i j}=\delta_{i j} p_{s \perp}+\left(p_{s \mid 1}-p_{s \perp}\right) b_{i} b_{j}
$$

where $\delta_{\mathrm{ij}}$ is the Kronecker delta. Equation (10) states that in the gyrotropic approximation there are only two independent pressure components, $\mathrm{p}_{\mathrm{s} \perp}$ and $\mathrm{p}_{\mathrm{sll}}$, representing average random energy components parallel and perpendicular to the macroscopic magnetic field. The heat flow equation yields the following condition:

$$
\varepsilon_{i m n} Q_{s j k m}+\varepsilon_{j m n} Q_{\text {sikm }}+\varepsilon_{\text {kmon }} Q_{\text {sijm }}=0
$$

This condition is satisfied by the following form of the heat flow tensor:

$$
Q_{s i j k}=q_{s \perp}\left(\delta_{i j} b_{k}+\delta_{i k} b_{j}+\delta_{j k} b_{i}\right)+\left(q_{s I I}-3 q_{s \perp}\right) b_{i} b_{j} b_{k}
$$

This functional form means that in the gyrotropic approximation the heat flow tensor has only two independent components, $\mathrm{q}_{\mathrm{s \perp}}$ and $\mathrm{q}_{\mathrm{sil}}$, representing the field aligned flow of parallel and perpendicular energy components.

In the polar ionosphere magnetic field curvature effects can be neglected, therefore one obtains:

$$
\frac{\partial b_{i}}{\partial x_{i}}=-\frac{b_{i}}{B} \frac{\partial B}{\partial x_{i}}
$$


and

$$
b_{j} \frac{\partial b_{i}}{\partial x_{j}}=\frac{1}{B} \frac{\partial B}{\partial x_{i}}-\frac{1}{B} \frac{\partial B}{\partial x_{j}} b_{i} b_{j}
$$

Substituting (8), (10), and (12) into the transport equation system ((2) to (5)) and using Grad's /28/ closing relation (eq. 6) the following closed set of gyrotropic transport equations are obtained:

$$
\begin{aligned}
& \mathrm{m}_{\mathrm{s}} \frac{\partial \mathrm{n}_{\mathrm{s}}}{\partial \mathrm{t}}+\mathrm{m}_{\mathrm{s}} B \frac{\partial}{\partial \mathrm{z}}\left(\frac{\mathrm{n}_{\mathrm{s}} \mathrm{u}_{\mathrm{s}}}{\mathrm{B}}\right)=\mathrm{m}_{\mathrm{s}} \dot{S}_{\mathrm{s}} \\
& m_{s} n_{s} \frac{\partial u_{s}}{\partial t}+m_{s} n_{s} u_{s} \frac{\partial u_{s}}{\partial z}+\frac{\partial p_{s I}}{\partial z}-\left(p_{s \|}-p_{s \perp}\right) \frac{1}{B} \frac{d B}{d z}-m_{s} n_{s} G_{\| l}-e_{s} n_{s} E_{\| l}=\dot{M}_{s \|} \\
& \frac{\partial p_{s i}}{\partial t}+B \frac{\partial}{\partial z}\left(\frac{u_{s} p_{s \|}+q_{s i}}{B}\right)+2 p_{s \|} \frac{\partial u_{s}}{\partial z}+2 q_{s \perp} \frac{1}{B} \frac{d B}{d z}=\dot{p}_{s \|} \\
& \frac{\partial \mathrm{p}_{\mathrm{si}}}{\partial \mathrm{t}}+\mathrm{B} \frac{\partial}{\partial \mathrm{z}}\left(\frac{\mathrm{u}_{\mathrm{s}} \mathrm{p}_{\mathrm{su}}+\mathrm{q}_{\mathrm{su}}}{\mathrm{B}}\right)+2 \mathrm{p}_{\mathrm{su}} \frac{\partial \mathrm{u}_{\mathrm{s}}}{\partial \mathrm{z}}+2 \mathrm{q}_{\mathrm{s \perp}} \frac{1}{\mathrm{~B}} \frac{\mathrm{dB}}{\mathrm{dz}}=\dot{\mathrm{p}}_{\mathrm{sl}}
\end{aligned}
$$

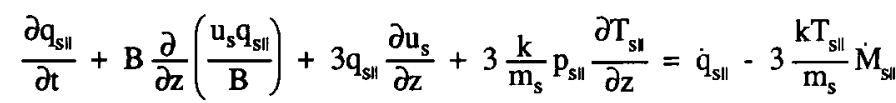

$$
\begin{aligned}
& \frac{\partial q_{s \perp}}{\partial t}+B \frac{\partial}{\partial z}\left(\frac{u_{s} q_{s \perp}}{B}\right)+q_{s \perp} \frac{\partial u_{s}}{\partial z}+\frac{k_{s l}}{m_{s}} \frac{\partial T_{s \perp}}{\partial z}-\left(u_{s} q_{s \perp}+\frac{k_{s \perp}}{m_{s}}\left(T_{s u}-T_{s \perp}\right)\right) \frac{1}{B} \frac{d B}{d z}=\dot{q}_{s \perp}-\frac{k T_{s \perp}}{m_{s}} M_{s t}
\end{aligned}
$$

Here $\mathrm{k}$ is the Boltzmann's constant, $\mathrm{z}$ is the distance along the flux tube, while $T_{s_{L}}=p_{s \mathrm{~s}} / \mathrm{kn}_{\mathrm{s}}$ and $\mathrm{T}_{\mathrm{stl}}=\mathrm{p}_{\mathrm{sl}} / \mathrm{kn}_{\mathrm{s}}$ refer to the perpendicular and parallel kinetic temperatures, respectively. Equations (15) to (20) describe the evolution of the six independent functions characterizing the gyrotropic twenty moment approximation: $n_{\mathrm{s}}, \mathrm{u}_{\mathrm{s}}, \mathrm{p}_{\mathrm{s} \perp}, \mathrm{p}_{\mathrm{sll}}, \mathrm{q}_{\mathrm{s} \perp}$ and $\mathrm{q}_{\mathrm{sll}}$ These equations reveal an interesting new result; the gyrotropic twenty moment approximation are identical to the transport equations obtained for the gyrotropic sixteen moment approximation by Oraevskii et al. $23 /$ and later by Demars and Schunk $26 \%$. The same equations were also used recently by Ganguli and Palmadesso $21 /$ and by Ganguli et al. $/ 22 /$ in the first application of the sixteen moment equations to polar wind conditions. It should be noted that Ganguli and Palmadesso /21/ and Ganguli et al. /22/ used different heat flow components, defined as

$$
\mathrm{h}_{\mathrm{sIl}}=\frac{\mathrm{q}_{\mathrm{sll}}}{2 \mathrm{n}_{\mathrm{s}}} \quad \mathrm{h}_{\mathrm{s \perp}}=\frac{\mathrm{q}_{\mathrm{s \perp}}}{\mathrm{n}_{\mathrm{s}}}
$$

The gyrotropic twenty moment approximation can be simplified to yield conventionally used lower order transport equations. First of all the omnidirectional pressure and field aligned heat flow are defined as

$$
\mathrm{p}_{\mathrm{s}}=\frac{1}{3} \mathrm{p}_{\mathrm{sll}}+\frac{2}{3} \mathrm{p}_{\mathrm{s} \perp} \quad \mathrm{q}_{\mathrm{s}}=\frac{1}{2} \mathrm{q}_{\mathrm{s} \|}+\mathrm{q}_{\mathrm{s} \perp}
$$

Assuming that the heat flow is isotropic, i.e.

$$
\mathrm{q}_{\mathrm{sll}}=\frac{6}{5} \mathrm{q}_{\mathrm{s}} \quad \mathrm{q}_{\mathrm{s} \perp}=\frac{2}{5} \mathrm{q}_{\mathrm{s}}
$$

one obtains the gyrotropic thirteen moment approximation. The additional assumption of isotropic pressure and negligible heat flow, i.e.,

$$
\mathrm{q}_{\mathrm{s}}=0 \quad \mathrm{p}_{\mathrm{su}}=\mathrm{p}_{\mathrm{s} \perp}=\mathrm{p}_{\mathrm{s}}
$$

yields the five moment (or hydrodynamic) approximation.

Table 1 summarizes the main characteristics of the presently published time-dependent polar wind models. A brief study of Table 1. reveals that even though considerable progress has been achieved in time dependent polar wind modeling, there is still considerable room to improve the present generation of models. It should be noted that most of the presently available polar wind models (with the exception of the two hydrodynamic models $/ 15,16 /$ ) are unable to describe the transition region, where the ionospheric plasma conditions change from stationary photochemical equilibrium to high speed flow conditions, therefore an already established ion flow has to be introduced at the lower boundary. 
TABLE 1 Comparison of the Existing "Non-Classical" Polar Wind Models

\begin{tabular}{|c|c|c|c|c|c|c|}
\hline & $\begin{array}{l}\text { Mitchell \& } \\
\text { Palmadesso } \\
1983 / 11 /\end{array}$ & $\begin{array}{l}\text { Zinin } \\
\text { et al. } \\
1985 / 15 /\end{array}$ & $\begin{array}{l}\text { Gombosi } \\
\text { et al. } \\
1985 / 16 /\end{array}$ & $\begin{array}{l}\text { Singh \& } \\
\text { Schunk } \\
1985 / 12 /\end{array}$ & $\begin{array}{l}\text { Ganguli \& } \\
\text { Palmadesso } \\
1987 \text { /21/ }\end{array}$ & $\begin{array}{l}\text { Gombosi } \\
\text { \& Schunk } \\
1988 / 19 /\end{array}$ \\
\hline $\begin{array}{l}\text { Dynamic } \\
\text { components }\end{array}$ & $\mathrm{H}^{+}, \mathrm{O}^{+}, \mathrm{e}$ & $\mathrm{H}^{+}, \mathrm{O}^{+}, \mathrm{e}$ & $\mathrm{H}^{+}, \mathrm{O}^{+}, \mathrm{e}$ & $\mathrm{H}^{+}, \mathrm{e}$ & $\mathbf{H}^{+}, \mathbf{e}$ & $\mathrm{H}^{+}, \mathrm{O}^{+}, \mathrm{e}$ \\
\hline $\begin{array}{l}\text { Static } \\
\text { components }\end{array}$ & none & $\begin{array}{l}\mathrm{O}_{2}^{+}, \mathrm{NO}^{+} \text {, } \\
\text { and neutrals }\end{array}$ & $\begin{array}{l}\text { neutrals } \\
\left(\mathrm{N}_{2}, \mathrm{O}_{2}, \mathrm{O}, \mathrm{H}\right)\end{array}$ & none & $\mathrm{O}^{+}$ & none \\
\hline $\begin{array}{l}\text { Transport } \\
\text { approximation }\end{array}$ & 13 moment & $\begin{array}{l}5 \text { moment with } \\
\text { heat conduction }\end{array}$ & $\begin{array}{l}5 \text { moment with } \\
\text { heat conduction }\end{array}$ & $\begin{array}{l}5 \text { moment } \\
\mathrm{T}=\text { constant }\end{array}$ & 16 moment & $\begin{array}{l}13 \text { moment } \\
\text { double adiabatic }\end{array}$ \\
\hline $\begin{array}{l}\text { Time } \\
\text { dependence }\end{array}$ & yes & yes & yes & yes & $\begin{array}{l}\text { yes, in the } \\
\text { latest version }\end{array}$ & yes \\
\hline $\begin{array}{l}\text { Collisional } \\
\text { regime }\end{array}$ & $\begin{array}{l}\text { collisions } \\
\text { unimportant }\end{array}$ & $\begin{array}{l}\text { collision } \\
\text { dominated }\end{array}$ & $\begin{array}{l}\text { collision } \\
\text { dominated }\end{array}$ & collisionless & $\begin{array}{l}\text { collisions } \\
\text { unimportant }\end{array}$ & collisionless \\
\hline $\begin{array}{l}\text { Field-aligned } \\
\text { currents }\end{array}$ & yes & no & $\begin{array}{l}\text { yes, in latest } \\
\text { version }\end{array}$ & no & yes & no \\
\hline $\begin{array}{l}\text { Altitude } \\
\text { range }\end{array}$ & $\begin{array}{l}800 \mathrm{~km}- \\
10 \mathrm{R}_{\mathrm{E}}\end{array}$ & $\begin{array}{l}126 \mathrm{~km}- \\
10 \mathrm{R}_{\mathrm{E}}\end{array}$ & $\begin{array}{l}200 \mathrm{~km}- \\
8000 \mathrm{~km}\end{array}$ & $\begin{array}{l}9000 \mathrm{~km}- \\
39000 \mathrm{~km}\end{array}$ & $\begin{array}{l}1500 \mathrm{~km}- \\
10 \mathrm{R}_{\mathrm{E}}\end{array}$ & $\begin{array}{l}1500 \mathrm{~km}- \\
9000 \mathrm{~km}\end{array}$ \\
\hline $\begin{array}{l}\text { Lower } \\
\text { boundary }\end{array}$ & $\begin{array}{l}n \& u \\
\text { specified }\end{array}$ & $\begin{array}{l}\text { chemical } \\
\text { equilibrium }\end{array}$ & $\begin{array}{l}\text { chemical } \\
\text { equilibrium }\end{array}$ & $\begin{array}{l}n \& \text { u } \\
\text { specified }\end{array}$ & $\begin{array}{l}\text { n \& u } \\
\text { specified }\end{array}$ & $\begin{array}{l}\mathbf{n} \& \mathbf{u} \\
\text { specified }\end{array}$ \\
\hline
\end{tabular}

\section{FIELD-ALIGNED CURRENT GENERATED POLAR WIND TRANSIENTS}

The modified hydrodynamic model of Gombosi et al. /16/ was used to study polar wind transients generated by field aligned currents, and some of the new results obtained from that study are presented in this section. The modified model simultaneously solves the time-dependent coupled continuity, momentum and energy equations for oxygen and hydrogen ions along diverging open magnetic field lines (the cross sectional area of a magnetic flux tube, $\mathrm{A}$, varies as $A \sim B^{-1}$, where $B$ is the magnetic field strength). It is assumed that the ion and electron gases can be considered to be perfect fluids. The model neglects magnetic field curvature effects and uses a gyrotropic five moment approximation. Using these assumptions the ion continuity, momentum and energy equations become:

$$
\begin{gathered}
\frac{\partial}{\partial t}\left(A m_{i} n_{i}\right)+\frac{\partial}{\partial z}\left(A m_{i} n_{i} u_{i}\right)=A m_{i} \dot{S}_{i} \\
\frac{\partial}{\partial t}\left(A m_{i} n_{i} u_{i}\right)+\frac{\partial}{\partial z}\left(A m_{i} n_{i} u_{i}^{2}\right)+A \frac{\partial p_{i}}{\partial z}=A n_{i}\left(A E_{\| 1}-m_{i} g\right)+A \dot{M}_{i}+A m_{i} u_{i} \dot{S}_{i} \\
\frac{\partial}{\partial t}\left(\frac{1}{2} A m_{i} n_{i} u_{i}^{2}+\frac{1}{\gamma_{i}-1} A p_{i}\right)+\frac{\partial}{\partial z}\left(\frac{1}{2} A m_{i} n_{i} u_{i}^{3}+\frac{\gamma_{i}}{\gamma_{i}-1} A u_{i} p_{i}\right)= \\
A n_{i} u_{i}\left(e E_{\|}-m_{i} g\right)+\frac{\partial}{\partial z}\left(A \kappa_{i} \frac{\partial T_{i}}{\partial z}\right)+A \dot{p}_{i}+A u_{i} \dot{M}_{i}+\frac{1}{2} A m_{i} u_{i}^{2} \dot{S}_{i}
\end{gathered}
$$

where the ' $i$ ' subscript refers to either hydrogen or oxygen ions, $\gamma_{i}$ is the specific heat ratio, $k$ is the heat conductivity, $\mathrm{e}$ is the particle charge, $\mathrm{g}$ is the magnitude of the local gravitational acceleration. It is assumed that the plasma is quasineutral, therefore the electron continuity equation can be replaced by a simple relation:

$$
\mathrm{n}_{\mathrm{e}}=\mathrm{n}\left(\mathrm{O}^{+}\right)+\mathrm{n}\left(\mathrm{H}^{+}\right)
$$

Next, a simple approximation for the field-aligned currents is introduced into the model. As done in previous studies $/ 11,21 /$, the present model assumes that the field-aligned current is entirely carried by the thermal plasma. Therefore, the electron velocity is expressed as

$$
u_{e}=\frac{1}{n_{e}}\left(n\left(O^{+}\right) u\left(O^{+}\right)+n\left(H^{+}\right) u\left(H^{+}\right)-\frac{j}{e}\right)
$$


where $j$ is the electric current density. Equation (28) is based on the assumption that the total flux tube current is conserved along the flux tube, i.e.

$$
\mathrm{j}=\mathrm{j}_{0} \frac{A_{0}}{\mathrm{~A}}
$$

where the ' 0 ' subscript refers to a reference altitude $\left(\mathrm{z}_{0}=200 \mathrm{~km}\right)$. In the present set of calculations $\mathrm{j}_{0}$ was a free parameter. In this approximation the electron momentum equation can be used to determine the electric field component parallel to the magnetic field:

$$
E_{\text {l }}=-\frac{1}{e n_{e}}\left[\frac{\partial}{\partial z}\left(p_{e}+m_{e} n_{e} u_{e}^{2}\right)+\frac{A^{\prime}}{A} m_{e} n_{e} u_{e}^{2}\right]+\frac{1}{e n_{e}} \frac{\partial}{\partial z}\left[\sum_{i=1}^{2} \frac{m_{e}}{m_{i}}\left(m_{i}\left(u_{e}-u_{i}\right) \dot{S}_{i}-\dot{M}_{i}\right)+\dot{M}_{e}\right]
$$

where $A^{\prime}$ denotes the spatial derivative of the flux tube cross sectional area function, $A$. The electron energy equation is:

$$
m_{e} n_{e} \frac{\partial T_{e}}{\partial t}=\left(\gamma_{e}-1\right) \frac{m_{e}}{k A} \frac{\partial}{\partial z}\left(A \kappa_{e} \frac{\partial T_{e}}{\partial z}\right)-m_{e} n_{e} u_{e} \frac{\partial T_{e}}{\partial z}-T_{e}\left(m_{e} \dot{S}_{e}+\frac{\gamma_{e}-1}{A_{e}} m_{e} n_{e} \frac{\partial\left(A u_{e}\right)}{\partial z}\right)+\left(\gamma_{e}-1\right) \frac{m_{e}}{k} \dot{p}_{e}
$$

The adopted neutral atmosphere model includes $\mathrm{N}_{2}, \mathrm{O}_{2}, \mathrm{O}$ and $\mathrm{H}$ taken from Banks and Kockarts /29/ The exospheric temperature of the stationary neutral atmosphere was chosen to be $1000 \mathrm{~K}$. The $\mathrm{O}^{+}$ions are produced by photoionization, while $\mathrm{H}^{+}$ions are created by the accidentally resonant $\mathrm{O}^{+}+\mathrm{H} \rightarrow \mathrm{O}+\mathrm{H}^{+}$charge exchange process. $\mathrm{O}^{+}$is chemically removed by the $\mathrm{O}^{+}+\mathrm{N}_{2} \rightarrow \mathrm{NO}^{+}+\mathrm{N}$ and the $\mathrm{O}^{+}+\mathrm{O}_{2} \rightarrow \mathrm{O}_{2}^{+}+\mathrm{O}$ reactions, followed by very fast dissociative recombinations of the $\mathrm{NO}^{+}$and $\mathrm{O}_{2}{ }^{+}$molecular ions. The $\mathrm{H}^{+}$is removed by the accidentally resonant $\mathrm{H}^{+}+$ $\mathrm{O} \rightarrow \mathrm{H}+\mathrm{O}^{+}$charge transfer reaction. The momentum and energy transfer collision terms describing ion-ion, ionneutral and electron-ion collisions, and the heat conductivities adopted in the present model were taken from $/ 30 /$ and 131/. It should be noted that these terms are strictly valid only in the collision-dominated region (below $\sim 2000 \mathrm{~km}$ ).

The model flux tube connects two infinite external reservoirs. The ions in the stationary lower reservoir (located at an altitude of $200 \mathrm{~km}$ ) are assumed to be in chemical and thermal equilibrium with the neutral atmosphere, while the electron temperature in this reservoir is set to $1000 \mathrm{~K}$. The upper reservoir (located at an altitude of $8000 \mathrm{~km}$ ) is a stationary, low pressure external medium, in effect representing a topside "vacuum-cleaner". Results are shown only for the region below $2500 \mathrm{~km}$, because this model starts to lose validity above a few thousand kilometers. The upper part of the integration region serves mainly as a buffer between the upper boundary and the physically valid region. A topside electron heat flux of $5 \times 10^{-3} \mathrm{ergs} \mathrm{cm}^{-2} \mathrm{~s}^{-1}$ is used to simulate energy deposition from the magnetosphere. It is also assumed that there is no ion heat flow between the upper reservoir and the ionospheric flux tube. The seven, coupled time-dependent partial differential equations were solved with a combined Godunov scheme/Crank-Nicholson method, using time splitting.

The initial condition in the model calculations was a steady plasma outflow along open magnetic field lines. This initial condition corresponds to a "classical" polar wind, describing supersonic $\mathrm{H}^{+}$flow at high altitudes. In order to investigate the various types of transient phenomena generated by field-aligned return currents both long and short lived current episodes were simulated. A long lasting field-aligned current can occur when a flux tube is convected along a return current region. An episodic current can occur when the flux tube is rapidly convected through a return current region. In order to study ion transient features the field-aligned current density value at $200 \mathrm{~km}$ was taken to be $j_{0}=10 \mu \mathrm{A} / \mathrm{m}^{2}$. This value is close to the typical observed current values $/ 33 /$, so these calculations simulate realistic field-aligned current events.

Fig. 1 shows snapshots of ion flux profiles following a long lasting return current event (when the return current was switched on at $t=0$ s and then remained constant for the rest of the calculation). The individual panels show snapshots of the transient ion fluxes at $t=5,10,20,30,45$ and 60 minutes after onset. Dashed curves correspond to $\mathrm{O}^{+}$ions, while the dotted curves refer to protons. The normalized fluxes were obtained as

$$
F_{i}=\frac{\left(R_{E}+z\right)^{3}}{\left(R_{E}+z_{0}\right)^{3}} n_{i} u_{i}
$$

where $R_{E}$ is the equatorial radius of earth and the reference altitude, $z_{0}$, was chosen to be $1000 \mathrm{~km}$. It can be seen tha $t$ the onset of the return current (the current is mainly carried by upward moving thermal electrons) rapidly generates a downward $\mathrm{O}^{+}$flow, while the $\mathrm{H}^{+}$ion fluxes remain practically undisturbed. The initial ambipolar electric field is mainly controlled by the major ion $\left(\mathrm{O}^{+}\right)$, therefore the light minor ions $\left(\mathrm{H}^{+}\right)$experience a large upward accelerating force. The return current generates a downward pointing electric field, which reduces the effect of the ambipolar field. The resulting new electric field profile is still capable to generate an upward motion of the light minor ion $\left(\mathrm{H}^{+}\right)$, but its reduced value results in a different ambipolar diffusive equilibrium for the heavy major species. In order to reach this new equilibrium the $\mathrm{O}^{+}$ions start to move downward, creating a downward flux. This transient flow pattern lasts about ten minutes, with a peak flux value of $\sim 5 \times 10^{8}$ ions $\mathrm{cm}^{-2} \mathrm{~s}^{-1}$. The transient moves up along the flux tube with a velocity of about $1.5 \mathrm{~km} / \mathrm{s}$. Even though most of the transient is gone after about 45 minutes, a long lasting slow downward adjustment (with small downward fluxes) continues even after an hour. 

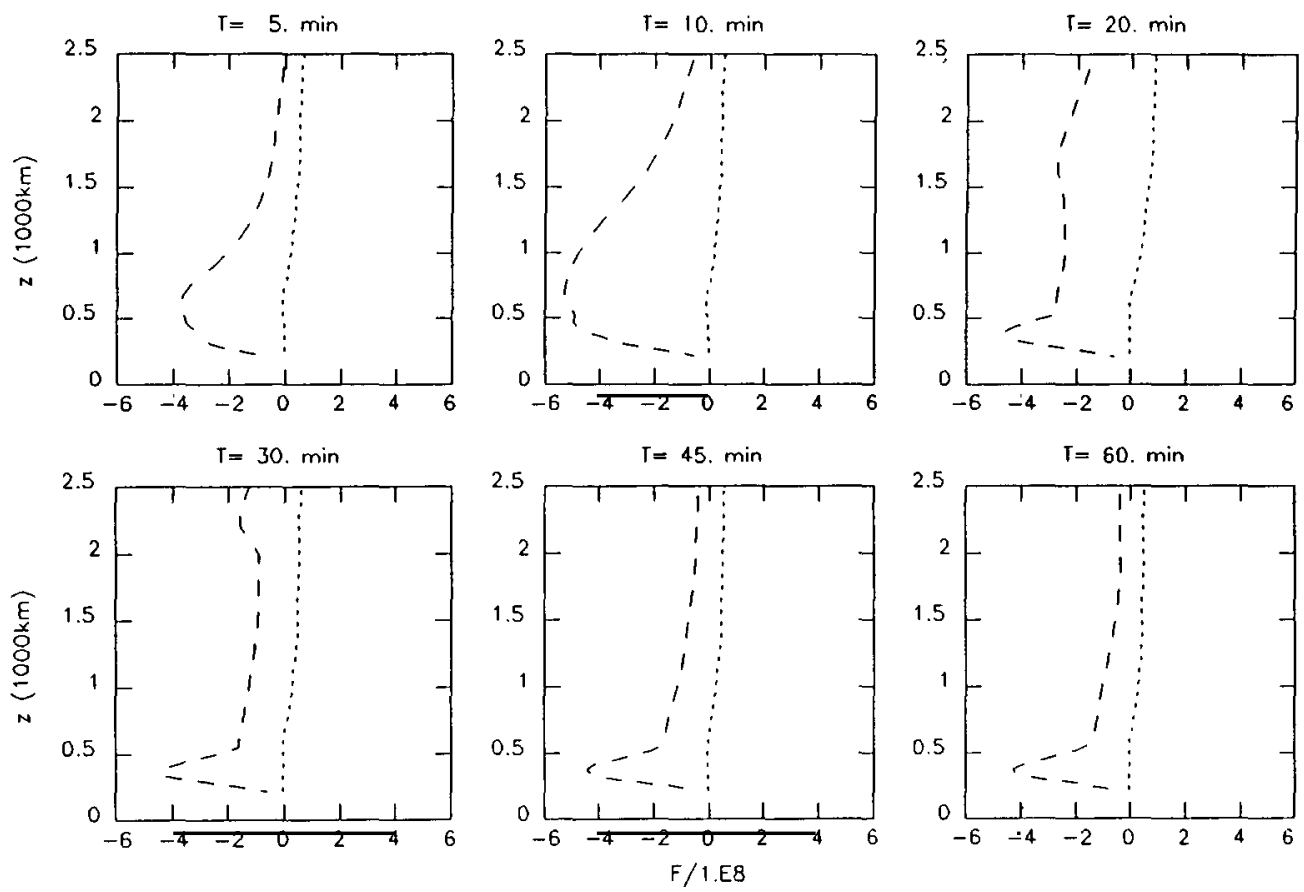

Fig. 1. Temporal evolution of ion transients following a long-lasting return current event. The individual panels show snapshots of the transient ion fluxes at $t=5,10,20,30,45$ and 60 minutes after onset. Dashed curves correspond to $\mathrm{O}^{+}$ions, while the dotted curve refers to protons
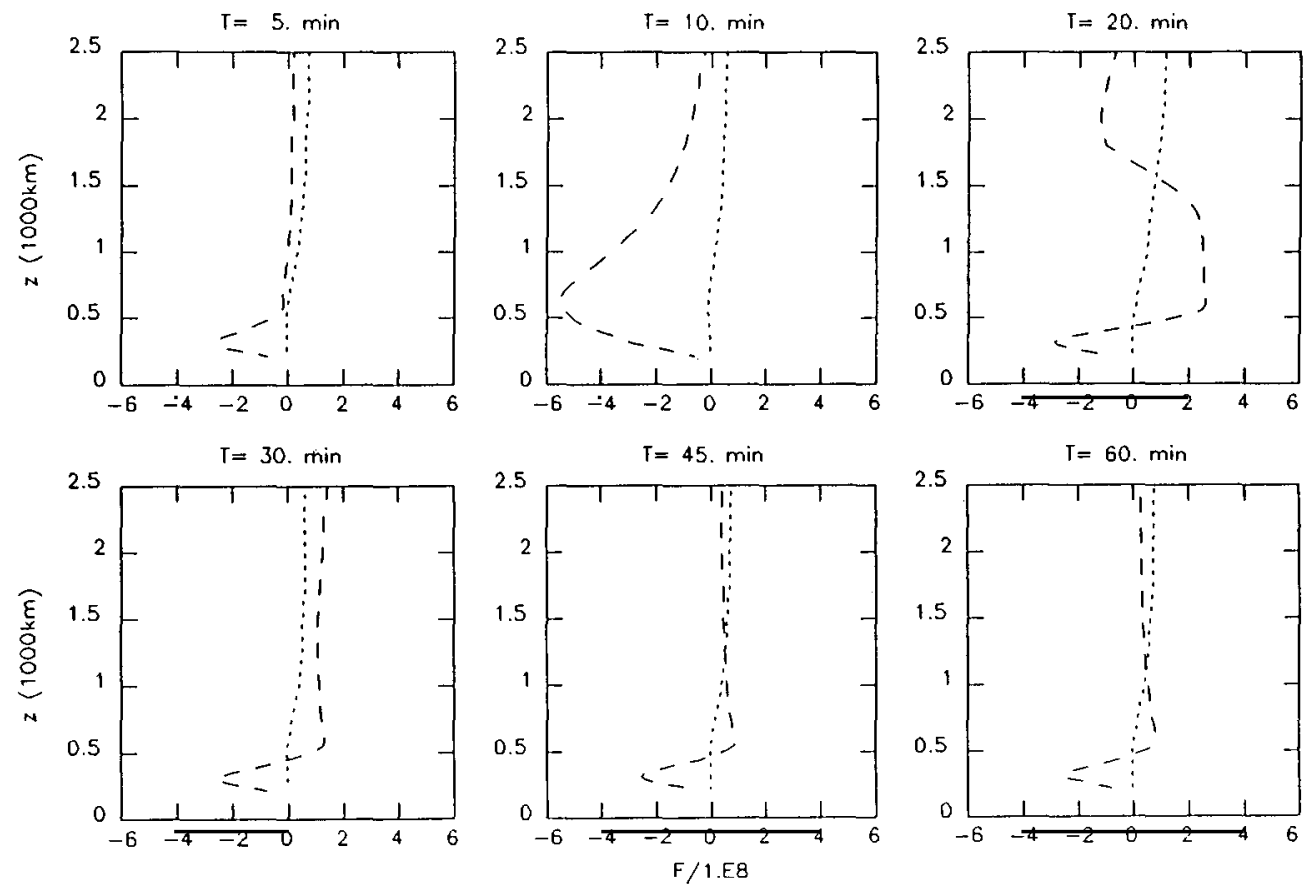

Fig. 2. Temporal evolution of ion transients following a short duration return current event. The individual panels show snapshots of the transient ion fluxes at $t=5,10,20,30,45$ and 60 minutes after onset. Dashed curves correspond to $\mathrm{O}^{+}$ions, while the dotted curve refers to protons 
Short duration retum current (when the return current is tumed on for only about five minutes) generated transient fluxes are displayed in Fig. 2. It can be seen that the initial phase of the transient is very similar to the long lasting case. However, after about 20 minutes when the return current has already ceased, a rapid "recovery" transient can be observed. This phase consists of upward heavy ion fluxes with a peak value of $\sim 10^{8}$ ions cm-2 $\mathrm{s}^{-1}$, which tries to restore the initial ion distribution. After about 45 minutes the transient fluxes have ceased and the initial flux profile is restored. The "recovery" transient moves upward with a velocity of about $3 \mathrm{~km} / \mathrm{s}$.

There are some other very interesting features generated by return currents. Fig. 3 shows the near-equilibrium solution at $\mathrm{t}=60$ minutes, obtained in the case of a long lasting return current. The six panels display flow velocity, hydrodynamic Mach number, particle flux (normalized to a reference altitude of $1000 \mathrm{~km}$ ), number density, pressure and temperature profiles between $200 \mathrm{~km}$ and $2500 \mathrm{~km}$. Inspection of Fig. 3 reveals that the topside electron temperature is about $1500 \mathrm{~K}$ less than it was before the onset of the return current because of adiabatic cooling. This drop in the electron temperature causes a significant decrease of the electron pressure, thus modifying the polarization electric field (mainly generated by the electron pressure gradient). At the same time the topside $\mathrm{H}^{+}$temperature is reduced by about $500 \mathrm{~K}$, while the $\mathrm{O}^{+}$temperature is increased by about $1500 \mathrm{~K}$. A very interesting consequence of the return current is this temperature inversion between the light and heavy ions: now the $\mathrm{O}^{+}$temperature significantly exceeds the $\mathrm{H}^{+}$temperature.

These results describing the transient behavior of the collision controlled high-latitude ionosphere, in response to the onset of field aligned return currents, are in good qualitative agreement with earlier predictions $/ 11,20,21 /$ The dominant process responsible for heavy ion transients is the change in the field aligned ambipolar electric field caused by the current. An increase in the ionospheric return current results in faster electron upflow, which in turn implies a more rapid expansion of the electron gas and therefore leads to cooler electron temperatures. The reduced electron temperature leads to a reduction of the ambipolar electric field, which generates a downward heavy ion flow.

It is interesting to note that the $\mathrm{H}^{+}$escape flux remains constant (within 10-20\%) during field-aligned return current events. The main reason for this insensitivity is that the light hydrogen ions are accelerated upwards by the ambipolar electric field, which is primarily controlled by the dominant ion species $\left(\mathrm{O}^{+}\right)$. The presence of field-aligned currents generates only relatively small changes in the parallel electric field profile: these modifications are strong enough to drive transient major ion flows (which in steady state experience only a small net acceleration), but they are not adequate to change the acceleration pattern of minor ions (in other words the upward accelerating force acting on $\mathrm{H}^{+}$ ions might be slightly increased or reduced by field-aligned currents, but the resulting force will still accelerate the hydrogen ions upward).

An interesting consequence of the large steady ionospheric return current is the substantial modification of the temperature profiles. It was already mentioned that the electron temperature decreases due to increased adiabatic cooling caused by faster electron upflow. At the same time the major ion $\left(\mathrm{O}^{+}\right)$temperature increases, while the light minor ions $\left(\mathrm{H}^{+}\right)$exhibit a temperature decrease (see Fig. 3). This behavior can be understood in terms of low altitude frictional heating. In the strongly collisionally coupled low altitude region $(z<500 \mathrm{~km})$ the upward flowing electrons frictionally heat the the neutrals and the ions. As it can be seen from Fig. 3 there are practically no hydrogen ions at this altitude range, consequently the electron-ion friction heats the $\mathrm{O}^{+}$population, while the $\mathrm{H}^{+}$gas receives very little direct heating. This heating significantly reduces the $\mathrm{O}^{+}$heat loss to the neutrals in the low altitude region, therefore it also reduces the downward heat flow from higher altitudes (where electron-ion collisions heat the ion population).
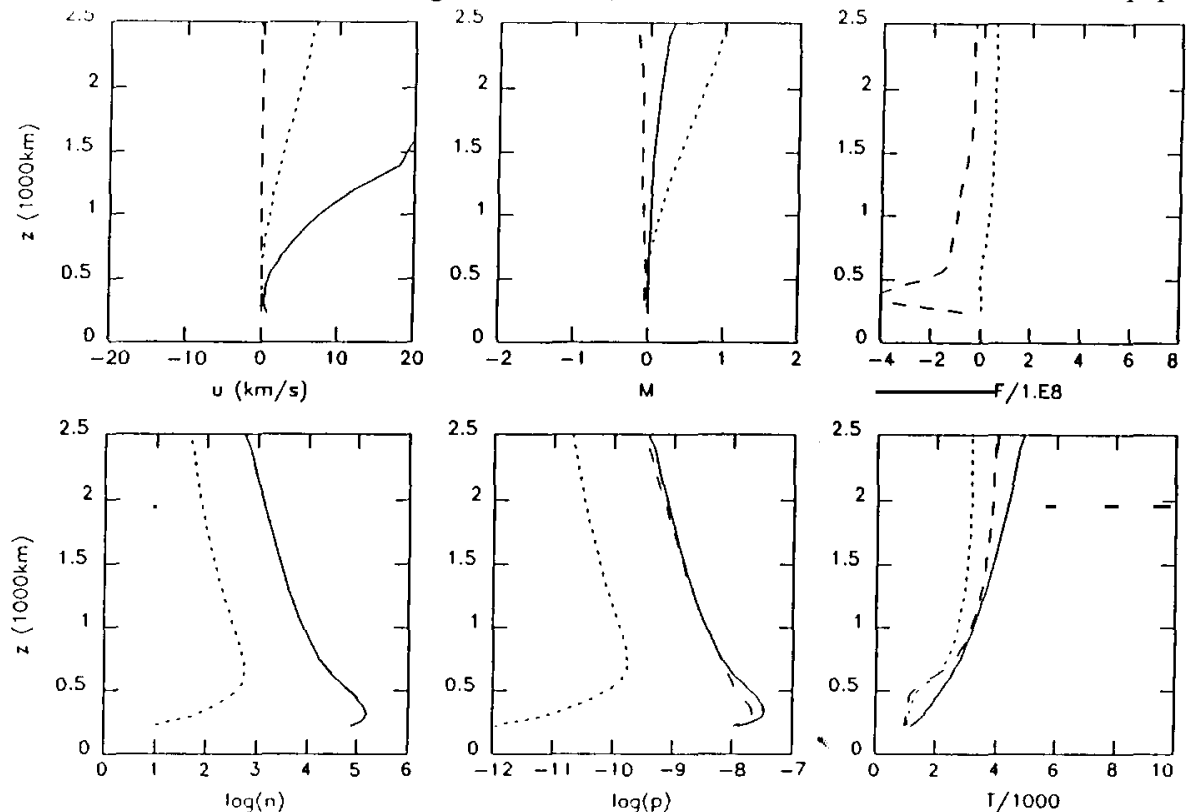

Fig. 3. Near-equilibrium solution at $t=60$ minutes obtained in the case of a long lasting return current . The six panels display flow velocity, hydrodynamic Mach number, particle flux (normalized to a reference altitude of 1000 $\mathrm{km}$ ), number density, pressure and temperature profiles between $200 \mathrm{~km}$ and $2500 \mathrm{~km}$. Solid lines represent electrons, dashed lines correspond to oxygen ions, while dotted lines denote hydrogen ions 
The reduction of the low altitude heat sink results in an $\mathrm{O}^{+}$temperature increase. It can also be seen that after 60 minutes the solution has not reached steady-state yet, therefore the reduced ambipolar electric field still drives a small downward $\mathrm{O}^{+}$flow (see the Mach number panel of Fig. 3). The $\mathrm{H}^{+}$ions are mainly heated by the electron population, therefore the decreased electron temperature eventually leads to reduced $\mathrm{H}^{+}$temperatures. The end result of this very interesting interplay of various species is an unusual ion temperature inversion: at higher altitudes (above $1000 \mathrm{~km}$ ) the heavy ion temperature exceeds the light ion temperature. In a sense this effect is generated by low altitude frictional heating, which represents a dissipative "resistance" in the electric circuit.

Finally, it is interesting to note that our earlier time-dependent polar wind simulations /16-19/, as well as the present work, show that almost any low or high altitude disturbance (density depletion, heating, field aligned current, etc) will eventually generate heavy ion flows with peak values which usually exceed the "classical" $\mathrm{H}^{+}$escape flux. One could conclude that if the polar ionosphere is disturbed, it produces heavy ion flows. The reason is quite clear: in the steady-state polar wind case the high altitude electron temperature is nearly constant, therefore the ambipolar electric field is primarily controlled by the electron density distribution (and consequently by the major ion density profile). Almost any disturbance will, at least temporarily, change these conditions. The ambipolar field (and the major ion distribution) will react to the changed conditions and in this process a part of the $\mathrm{O}^{+}$population is redistributed. At the same time the $\mathrm{H}^{+}$distribution and escape flux is only slightly modified, because these ions are strongly accelerated upward even during steady-state conditions.

\section{SUMMARY}

The effects of magnetic field-aligned return currents on the high latitude, collision controlled ionosphere were investigated using a time-dependent, multispecies hydrodynamic model. The model simultaneously solves the coupled continuity, momentum and energy equations for $\mathrm{H}^{+}, \mathrm{O}^{+}$and electrons, including frictional interactions, collisional conductivities and variable temperatures. From the numerical simulations we found the following:

(1) Field-aligned currents generate large transient fluxes of the major ion $\left(\mathrm{O}^{+}\right)$with peak values well exceeding the $\mathrm{H}^{+}$ escape flux. The typical duration of these transient events is about 30 minutes. At the same time the light minor ion $\left(\mathrm{H}^{+}\right)$distribution and escape flux are only slightly modified.

(2) Ionospheric return currents generate downward flows of heavy ions in the topside ionosphere. During these events the electron temperature decreases because faster upflow creates increased adiabatic cooling. The $\mathrm{O}^{+}$ population is heated by low altitude ion-electron friction thus significantly reducing the low altitude heat sink. Electron - proton collisions represent the main energy source of the $\mathrm{H}^{+}$population, therefore smaller electron temperatures result in decreased $\mathrm{H}^{+}$heating and thus in reduced $\mathrm{H}^{+}$temperatures. The combined effect of these processes is an interesting $\mathrm{H}^{+}-\mathrm{O}^{+}$temperature inversion.

(3) Short duration ionospheric return current events also generate significant $\mathrm{O}^{+}$upwellings after the return current reduces to insignificant levels.

\section{ACKNOWLEDGEMENTS}

This work was supported by NASA grants NGR23-005-015 and NAG5-472 and NSF grants ATM-8508753 and ATM-8810510. Acknowledgement is also made to the National Center for Atmospheric Research, sponsored by the National Science Foundation, for the computing time used in this research.

\section{REFERENCES}

1. W.I. Axford, The polar wind and the terrestrial helium budget, J. Geophys. Res. 73, 6855 (1968)

2. P.M. Banks and Holzer, T.E., The polar wind, L. Geophys. Res, 73, 6846 (1968)

3. J.H. Hoffman, Studies of the composition of the ionosphere with a magnetic deflection mass spectrometer, Int. J. Mass Spectrom. Ion. Phys., 4, 315 (1970)

4. E.G. Shelley, R.D. Sharp, and R.G. Johnson, Satellite observations of an ionospheric acceleration mechanism, Geophys. Res. Lett., 3, 654 (1976)

5. A.G. Ghielmetti, R.G. Johnson, R.D. Sharp, and E.G. Shelley, The latitudinal, diurnal, and altitudinal distributions of upward flowing energetic ions of ionospheric origin, Geophys. Res. Lett, 5, 59 (1978)

6. T. Nagai, J.H. Waite, J.L. Green, C.R. Chappell, R.C. Olsen, and R.H. Comfort, First measurements of supersonic polar wind in the polar magnetosphere, Geophys. Res. Lett., 11, 669 (1984)

7. M. Lockwood, J.H. Waite, T.E. Moore, J.F.E. Johnson, and R.C. Chappell, A new source of suprathermal $\mathrm{O}^{+}$ions near the dayside polar cap boundary, L.Geophys. Res., 90, 4099 (1985)

8. A.W. Yau, B.A. Whalen, W.K. Peterson, and E.G. Shelley, Distribution of upflowing ionospheric ions in the high-altitude polar cap and auroral ionosphere, J. Geophys. Res, 89, 5507 (1984)

9. W.K. Raitt and R.W. Schunk, Composition and characteristics of the polar wind, in Energetic Ion Composition in the Earth's Magnetosphere ed.R.G. Johnson, Terra, Tokyo, p99, 1983.

10. A.R. Barakat and R.W. Schunk, Effect of hot electrons on the polar wind, L. Geophys. Res, 88 (1971, 1984)

11. H.G. Mitchell and P.J. Palmadesso, A dynamic model for the auroral filed line plasma in the presence of field-aligned current, I. Geophys. Res, 88, 2131 (1983)

12. N. Singh and R.W. Schunk, Temporal behavior of density perturbations in the polar wind, L.Geophys. Res. $90,6487(1985)$ 
13. N. Singh and R.W. Schunk, Ion acceleration in expanding ionospheric plasmas, in Ion Acceleration in the Ionosphere and Magnetosphere, ed. T. Chang, Geophysical Monograph 38, AGU, Wastrington, D.C., P362, T986.

14. G.V. Khazanov, M.A. Koen, U.V. Konikov, and I.M. Sidonov, Simulation of ionosphere - plasmasphere coupling taking into account ion inertia and temperature anisotropy, Planet. Space Sci., 32, 585 (1984)

15. L.V. Zinin, Yu.I. Galperin, K.S. Latyshev, and S.A. Grigoriev, Nonstationary field-aligned fluxes of thermal ions $\mathrm{O}^{+}$and $\mathrm{H}^{+}$outside the plasmapause: refinement to the polar wind theory, in: Results of the ARCAD-3 Project and the Recent Programmes in Magnetospheric and Ionospheric Physics, Cepactures, Toulouse, p391, 1985.

ARCAD-3 Project and the Recent Programmes in Magnetospheric and Ionospheric Physics, Cepadues, Toulouse, p391, 1985.

16. T.I. Gombosi, T.E. Cravens, and A.F. Nagy, A time-dependent theoretical model of the polar wind: Preliminary results, Geophys. Res. Lett., 12, 167 (1985)

17. T.I. Gombosi, T.E. Cravens, A.F. Nagy, and J.H. Waite, Time-dependent numerical simulation of hot ion outflow from the polar ionosphere, in Ion Acceleration in the Magnetosphere and Ionosphere ed. T. Chang, Geophysical Monograph 38, AGU publication, p366, 1986.

18. T.I. Gombosi and T.L. Killeen, Effects of thermospheric motions on the polar wind: A time-dependent numerical study, L. Geophys. Res, 92, 4725 (1987)

19. T.I. Gombosi and R.W. Schunk, A comparative study of plasma expansion events in the polar wind, Planet. Space, Sci., 36, 753 (1988)

20. R.W. Schunk, J.J. Soika, and M.D. Bowline, Theoretical study of the effect of ionospheric return currents on the electron temperature, J. Geophys. Res., 92, 6013 (1987)

21. S.B. Ganguli and P.J. Palmadesso, Plasma transport in the auroral return current region, J. Geophys. Res., 92, 8673 (1987)

22. S.B. Ganguli, H.G. Mitchell, and P.J. Palmadesso, Behavior of ionized plazma in the high altitude topside ionosphere: The polar wind, Planet. Space Sci, 35, 703 (1987)

23. V. Oraevskii, R. Chodura, and W. Feneberg, Hydrodynamic equations for plasmas in strong magnetic fields, I., Plasma Phys. 10, 819 (1968)

24. J.M. Burgers, Flow equations for composite gases, Academic Press, New York, 1969.

25. R.W. Schunk, Mathematical structure of transport equations in multispecies fluids, Rev. Geophys. Space Phys., 15, 429 (1977)

26. H.G. Demars and R.W. Schunk, Transport equations for multispecies plasma based on individual biMaxwellian distributions, J. Phys. D., 12, 1051 (1979)

27. A.R. Barakat and R.W. Schunk, Transport euations for multicomponent anisotropic space plasmas: A review, Plasma Phys, 24, 389 (1982)

28. H. Grad, On the kinetic theory of rarefied gases, Comm. Pure Appl. Math, 2. 331, 1949.

29. P.M. Banks and G. Kockarts, Aeronomy, Academic Press, New York, 1973.

30. W.J. Raitt, R.W. Schunk, and P.M. Banks, A comparison of the temperature and density structure in the high and low speed thermal proton flows, Planet. Space Sci., 23, 1103 (1975)

32. R.W. Schunk and A.F. Nagy, Ionospheres of terrestrial planets, Rev, of Geophys, and Space Phys, 18,813 (1980)

33. T. Iijima and T.A. Potemra, The amplitude distribution of field-aligned currents at northern high latitudes observed by Triad, J.Geophys. Res., 81, 2165 (1976) 